\title{
The Influence of Increased Intensity Levels on the Attitude of High School Females toward Aerobic Dance Lessons
}

\author{
by \\ Krysztof Skalik ${ }^{1}$, Karel Frömel ${ }^{2}$, Jiri Stelze ${ }^{3}$, Jana Pelclová ${ }^{2}$ Dorota Groffik ${ }^{1}$
}

\begin{abstract}
Available evidence suggests that interest and participation, especially in vigorous physical activity, declines with age during adolescence. This negative attitude toward vigorous physical activity is especially prevalent among female adolescents. This study investigates how increasing intensity levels of aerobic dance, a popular physical education choice of female students, influence the attitude of female high school students toward the activity.

A total of 313 female high school students from eight schools (age 16.32 \pm 1.74 ; weight-kg 53.73 \pm 7.58 ; height-cm $\left.164.37 \pm 5.61 ; B M I-k g / m^{2} 19.87 \pm 2.55\right)$ participated in the study. Student intensity levels during the aerobic dance lesson were monitored using heart rate monitors, accelerometers and pedometers, and the influence of intensity level on attitude toward aerobic dance was measured by use of a standardized questionnaire. The results clearly show that increasing intensity levels did not diminish the positive attitude of female students toward aerobic dance.
\end{abstract}

Key words: physical intensity, active energy expenditure, monitoring of heart rate, accelerometer, pedometer

\section{Introduction}

Recent research findings indicate that while both the amount and intensity level of physical activity (PA) declines significantly during adolescence for both sexes (Amstrong \& Welsman, 2006; Trost et al., 2002), the highest rate of decline is found among adolescent females (Spear, 2002; Strauss, Rodzilsky, Burack, \& Colin, 2001; Frömel, Novosad, \& Svozil, 1999; Sallis \& Owen, 1999). Some studies suggest that the decline begins as early as 6 years of age (Frömel, Stelzer, Groffik, \& Ernes, 2008; Saris et al.,1986), progressively worsens with age (Sallis, Prochazka, \& Taylor, 2000) and is at its lowest in early adolescence (Sallis, 2000; Stone, et al, 1998). These findings are consistent with evidence that female students, especially adolescents, harbor a strongly negative attitude toward physical education (PE). For example, Stelzer, et al. (2004) found in a study of 1,107 high school students from four countries that the attitude of United States students toward PE was more negative than that of their international counterparts and the attitude of females from each of the four countries was more negative than that of male students. Additionally, Frömel, Novosad and Svozil (1999) found that the negative feelings toward PA among female students increases with an increase in the level of physical

\footnotetext{
I - Academy of Physical Education, Katowice, Poland

2 - Faculty of Physical Culture, Palacky University, Olomouc, Czech Republic

3 - Valdosta State University, USA
} 


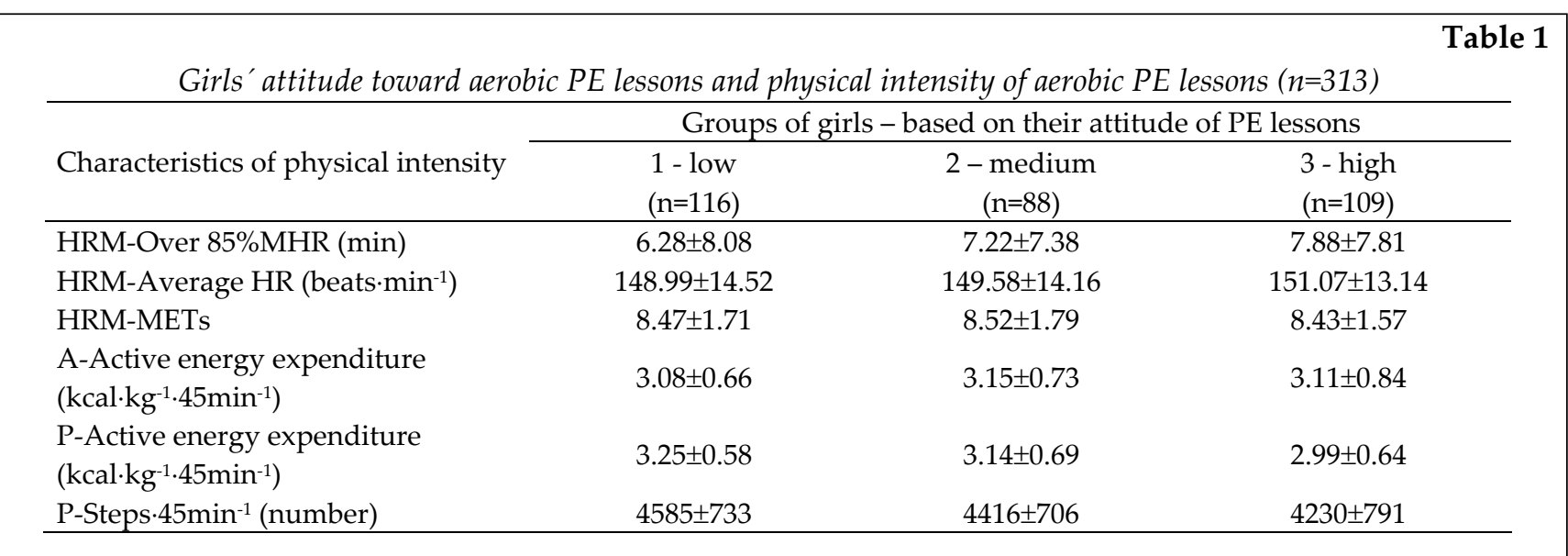

intensity, even though the intensity of the activity is appropriate to their age and grade.

A negative attitude toward PA is seen as a major deterrent to adopting a healthy lifestyle. As suggested by Bandura, 1996; Dewey, 1933; and Pajares, 1992, attitude and the individual's underlying belief system are considered the best indicators of the decisions people will make throughout their lives. This negativity, especially that harbored by female students, presents a daunting challenge to physical educators to find activities that appeal to today's youth (Centers for Disease Control and Prevention, 1997). One such promising activity is aerobic dance. It is not only a popular vehicle for promoting PA among female students, but evidence also shows that it incorporates an intensity level sufficient to promote appropriate aerobic health benefits (Bartoszewicz \& Frömel, 2006; Frömel, Formánková, \& Sallis, 2002; Fromel, Novosad, \& Svozil, 1999). The existing literature does not, however, investigate whether the popularity and positive attitude toward aerobic dance among female students changes as the intensity level of the activity increases. This study investigates how different intensity levels of aerobic dance influence attitudes of female high school students toward the lesson.

\section{Methodology}

\section{Sample Characteristics}

The sample population is made of 313 female students from eight, randomly selected high schools drawn from the Katowice region of Poland. In general, the sample is defined by the following metrics: Age, 16.32 \pm 1.74 ; Weight-kg, 53.73 \pm 7.58 ;

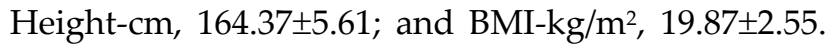

Only $4.79 \%$ of girls had BMI $>24-\mathrm{kg} / \mathrm{m}^{2}$ and $8.6 \%$ of girls showed $B M I<17 \mathrm{~kg} / \mathrm{m}^{2}$.

The high schools included in the study ranged in size from four located in towns with large enrollments, to four smaller schools located in villages. Physical education classes participating in the study were selected randomly from the participating schools. In each case, PE classes were taught by teachers holding appropriate university credentials; and were held three times per week for 45 minutes.. Student attendance, with the exception of those excused for health reasons, was mandatory at each school. Written consent from parents was required for student participation in the study and only two students from the sample refused to have their activity monitored.

\section{Study Design}

The logistical and statistical procedures used in the study were standard protocol. First, a threefold objective was established for classroom lessons: achieve the highest possible intensity of PA for each participant; efficiently use the time taken for each lesson; and attain full student participation in all activities. Second, PE teachers were allowed to choose from those aerobic dance lessons that were chosen as most popular by female students. Student influence on the choice of dance lesson was felt to be a strong motivational factor reflected in both performances during activity and post-activity attitude measurement (Prusak, Treasure, Darst, \& Pangrazi, 2004).

Next, students were fitted with monitoring devices prior to the start of aerobic dance class. Polar $\mathrm{S} 610^{\mathrm{TM}}$ heart rate monitors were used to measure maximum heart rate (MHR) and average heart rate HR. MHR was established using the universal formula (220-age). Average HR values were 


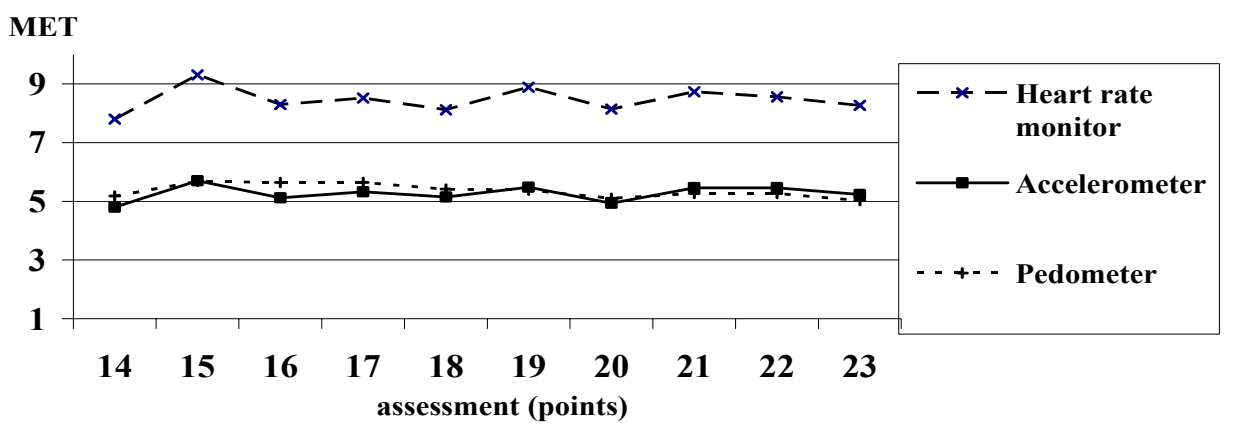

\section{Figure 1}

The association between girls' attitudes of the lessons ( $\mathrm{n}=313$ girls) and the intensity of physical load (METs) in aerobic dance lessons

converted to Physical Load in METs according to Ástrand and Rodahl (1977). Energy expended and distances traveled during the activity period were measured with Caltrac accelerometers and Omron HJ-102 pedometers, respectively. Statistical analysis of the data included one-way ANOVA, Scheffé, Spearman rank correlation and $\omega^{2}$ - coefficient omega squared tests (Tolson, 1980). Statistical analysis of the data was performed using Statistica 6.0 and SPSS 15.0 software.

At the conclusion of each lesson, participants were given a brief summary of the energy expended and then asked to complete an attitudinal survey to measure post-activity feelings toward aerobic dance. This standardized questionnaire (Figure 1) consists of 24 questions covering cognitive, emotional, health, social, relational, and creative dimensions. Participants also received a more detailed report on individual results at the next class period. The report included data on:

Heart rate activity as produced by the heart rate monitor. These data were shown in the form of a heart rate graph with zones for physical intensity, time of physical intensity in individual zones, and average heart rate highlighted.

Energy expended as produced by the accelerometer including metrics for total energy expended, active energy expended, relative active energy expended per $45 \mathrm{~min}\left(\mathrm{kcal}^{\circ} \mathrm{kg}^{-1} \cdot 45 \mathrm{~min}^{-1}\right)$, and the average METs value.

Distance traveled as shown by the pedometer in the form of the total number of steps taken.

\section{Results}

The high intensity levels during the dance aerobic lessons were achieved. All female students were on average $7.10 \mathrm{~min}$ over $85 \%$ of their MHR. The average heart rate was 150 beasts/min, active energy expenditure was $167.20 \mathrm{kcal} \cdot 45 \mathrm{~min}^{-1}$, relative energy expenditure was $3.11 \mathrm{kcal} \cdot \mathrm{kg}^{-1} \cdot 45 \mathrm{~min}^{-1}$ and average number of steps were 4404 per 45 minutes (Table 1). Such physical intensity is considered as vigorous PA levels with additional health benefits and is physiologically very beneficial. (it might be worth citing 1 or 2 authors here for reader follow up)

The results have shown that high physical intensity of girls PA during aerobic dance lessons does not negatively impact the female students' attitude toward the PE lessons. Yet, statistically significant associations toward the lesson were found between the measurements from the pedometers and the low attitude group. Active energy expenditure and the category of low attitude toward the lessons $\left(\mathrm{F}=4.71 ; \mathrm{p}=.009 ; \omega^{2}=.023\right.$; posthoc test for categories 1-3 $\mathrm{p}=.009$ ); and number of steps and the category of low attitude toward the lessons $\left(\mathrm{F}=5.43 ; \mathrm{p}=.005 ; \omega^{2}=.028\right.$; post-hoc test for categories 1-3 $\mathrm{p}=.005)$ measured with pedometers were statistically significant. We do not, however, regard these differences as practically significant. The pedometers (movement counters) have very low validity when used as an estimate of energy expenditure and intensity. They are not sensitive to the intensity, upwards and downwards movements and they don't sense movements of body parts other than the waist (Saris \& Binkhorst, 1977; Eston at al., 1997). However, they were used in the study for 
immediate feedback to the female students after the PE lesson.

The association between physical intensity in METs during the aerobic PE dance lessons and the female student's attitude toward the lessons is demonstrated by the curves of correlation between all monitoring devices (Figure 1). The curves confirm the high physical intensity did not negatively affect the attitude toward the lessons.

\section{Discussion}

This study clearly supports the assumption that increasing the intensity level of aerobic dance does not reduce its popularity with female high school students. It should be considered, therefore, an excellent vehicle for promoting healthy exercise among unenthusiastic adolescents.

For purposes of this study, attitude was used as the proxy for popularity and measured using a 24question standardized questionnaire (Figure 2). Each question was assigned a value of one point and required a positive, yes, or negative, no, response. Questionnaire results for the sample $(n=313)$ were divided into four attitude groups. As shown in Table 1 , those students expressing a positive attitude toward aerobic dance in the lowest attitude group $(n=116)$ tabulated questionnaire values $\leq 17$ points; the middle attitude group $(\mathrm{n}=88)$ consists of values of 18 to19 points; and the highest attitude group ( $\mathrm{n}=109)$ consists of values $\geq 20$ points. The fourth grouping, the outliers who expressed a negative attitude toward aerobic dance, consists of only 17 students, or only $5.43 \%$ of the sample population.

Health and physical education professionals emphasize the importance of physical activity to a healthy lifestyle. The U.S. Department of Health and Human Services (HHS) recommends that adolescents should engage in 60 minutes or more of physical activity daily and that most of the 60 minutes should be in the moderate to vigorous intensity range with at least 3 days per week of purely vigorous physical activity. Vigorous is defined by this agency as breathing rapidly (2008). (it's better to cite CDC's paper or manuscript, rather than cite the year it was produced)

More precise definitions for physical activity intensity levels involve heart-rate measurement. The U.S. Center for Disease Control (CDC) (2008) defines moderate intensity levels as a range of $50-70 \%$ of MHR and vigorous intensity levels from $70-85 \%$ of MHR. The CDC further suggests that the vigorous intensity levels improve aerobic capacity and, thereby, promote the greatest health benefit.

This study used the more precise measurement of physical activity, heart rate in beats per minute, to delineate intensity levels. During the 45 minute PE classes, $85 \%$ of the participants in the lowest attitude group sustained a maximum heart rate for 6.28 minutes; the middle group sustained this level for 7.22 minutes; and the highest group for 7.88 minutes. Given the mean age of 16.3 years, the 148.99 beats per minute (BPM) average heart rate of the lowest attitude group is $73.14 \%$ of MHR; the $149.58 \mathrm{BPM}$ average heart rate of the middle group is $73.43 \%$ of MHR; and the 151.07 BPM average heart rate of the highest group is $74.16 \%$ of their MHR. These vigorous heart rate levels are consistent with the CDC (2008) and the HHS (2008) recommendations of promoting the greatest health benefits.

The most often used measure of energy expenditure is "metabolic equivalent" (MET). This metric is expressed as the energy cost of physical activities of Resting Metabolic Rate (RMR) and is defined as rate of energy consumption during a specific PA (HHS, 2008). Additionally, light-intensity physical activity is defined as 1.1 to 2.9 METs; moderate-intensity activity from 3.0 to $5.9 \mathrm{METs}$; and vigorous-intensity activity as 6.0 or more METs. The MET values produced by the heart-rate monitors used in this study were 8.47 for the lowest attitude group; 8.52 for the middle group; and 8.43 for the highest attitude group. These values are above the minimum for vigorous-activity levels recommended by Ainsworth et al. (2000) and the HHS (2008), and again reinforce the choice of aerobic dance as a PE lesson.

The MET concept in the form of MET-min per week is also used in health guidelines published by the HHS (2008). The range of 500 to 1000 MET-min of physical activity per week is considered to provide substantial health benefits and activity levels above this range provide even more physiological benefits (HHS, 2008). Data from this study show average MET-min values per lesson for the lowest attitude group of $381.15 ; 383.4$ for the middle group; and 379.3 for the highest attitude group. Converting these measurements to weekly equivalents using a multiple of three for the three PE lessons per week, produces weekly-equivalent METmin values of 1143, 1150, and 1138 for the three attitude groups, respectively. Comparing these 
values to HHS recommendations further confirms the health benefits gained from aerobic dance.

Pangrazi, Beighle and Sidman (2007) recommend 10,000 steps daily as an acceptable level for physical exercise. The pedometers used in this study produced an overall average number of steps taken during the lesson of 4,404. This is, in only a 45 minute class period, almost $45 \%$ of the daily standard recommended by Pangrazi et.al. The exercise level implied by this number of steps is not, however, supported by the accelerometer and heartrate monitor data shown in Table 1 . This inconsistency supports literature findings on the unreliability of pedometers as effective tool for measuring of energy expenditure and intensity levels because they are not sensitive to intense upward and downward body movements or movements of body parts above the waist (Saris \& Binkhorst, 1977; Eston at al., 1997).

Finally, it is important to note that even female students possessing severe obesity levels (BMI>30) reported an above average attitude toward aerobic dance. These students had average intensity levels of 5.84 METs, which translates to 262.8 MET-min per lesson or a weekly equivalent of 788.4 MET-min. This weekly equivalent is well within the 500 to 1000 MET-min a week recommended by HHS (2008).

\section{Conclusion}

Attitude, along with an individual's underlying belief system, are important determinants of what is considered appealing and the choices one makes. This notion is particularly relevant to female adolescents and the negative attitude of this group toward PE classes in general and increased physical activity during those classes in particular.
Using this perspective as its focal point, this study examined the question of whether increasing the physical intensity of a popular PE lesson, aerobic dance, reduced its popularity. Clearly, if popularity is diminished as high aerobic levels are induced, aerobic dance loses much of its appeal as a PE lesson choice. Conversely, if popularity levels are maintained, despite high intensity levels, aerobic dance becomes an important vehicle for exposing female students to salutary exercise and for conducting a successful PE class. This study produced strong evidence for the latter position.

The results of this study also suggest two important avenues for additional research. First, given the importance of student appeal in determining attitude toward and the ultimate success of PE lessons, research and creative effort should be directed toward identifying attractive physical activities that can be incorporated into PE lessons. Additionally, increased investigation into the impact of increased physical intensity on student attitude across a wide range of PE lessons would further enhance the process of choosing PE lessons that are both and salutary and successful.

\section{Research limits}

Due to ethical and organizational reasons, the research could not be carried out in a random sample of girls.

To calculate the MHR we used the universal formula, therefore the times of physical load above the anaerobic threshold tend to be slightly overestimated.

Girls and teachers felt more motivated to perform physical activity when being monitored and knowing they would receive individual feedback after the study.

\section{References}

Aiken, L. R. Attitudes and related psychosocial constructs. Thousand Oaks, CA: Sage. 2002.

Ainsworth, B. E. et al. Compendium of physical activities: An update of activity codes and MET intensities. Med Sci Sport Exer, 2000. 32(9), S498-S516.

Amstrong, N., \& Welsman, J. R. The physical activity patterns of European youth with reference to methods of assessment. Sports Med, 2006. 36(12), 1067-1086.

Ấstrand, P. O., \& Rodahl, K. Assessment of physical work capacity on the basis of tests. In D. B. Van Dalen (Ed.), Textbook of work physiology 1977. (pp. 331-365). New York, NY: McGraw-Hill.

Bandura, A. 1986. Social foundations of thought and action: A social cognitive theory. Englewood Cliffs, NJ: Prentice-Hall. 1986. 
Bartoszewicz, R., \& Frömel, K. Motor activity of junior high school students in the period of socio-economic transformations in Poland and the Czech Republic. Human Movement, 2006. 7(1), 14-24.

Center for Disease Control and Prevention 2008. Target Heart Rate and Estimated Maximum Heart Rate. Retrieved May 1, 2009 from http://www.cdc.gov/physicalactivity/everyone/measuring/heartrate.html.

Center for Disease Control and Prevention. 1997. Guidelines for school and community programs to promote lifelong physical activity among young people. Retrieve May 1, 2009 from http://www.cdc.gov/mmwr/preview/mmwrhtml/00046823.htm.

Dewey, J. How we think. Boston 1933. D. C. Health.

Eston, R. G., Rowlands, A. V., \& Ingledew, D. K. Validation of the Tritrac-R3D (TM) activity monitor during typical children's activities. In N. Armstrong, B. Kirby, \& J. Welsman (Eds.), Children and Exercise XIX 1997. (pp. 132-138). London: E \& FN Spon.

Frömel, K., Formánková, S., \& Sallis, J. F. Physical activity and sport preferences of 10 to 14-year-old children: A 5year prospective study. Acta Universitatis Palackianae Olomucensis Gymnica, 2002. 32(1), 11-16.

Frömel, K., Novosad, J., \& Svozil, Z. 1999. Pohybová aktivita a sportovní zájmy mládeže. Olomouc: Univerzita Palackého.

Frömel, K., Vasendova, J., Stratton, G., \& Pangrazi, R. P. Dance as a fitness activity: The impact of teaching style and dance form. Journal of Physical Education, Recreation and Dance, 2002. 73(5), 26-30, 54.

Frömel, K., Stelzer, J., \& Groffik, D., Ernest, J. Physical activity of children aged 6-8: The beginning of school attendance. The Journal of Research in Childhood Education, 2008. 23, 1, 29-40.

Pajares, M. F. Teacher's beliefs and educational research: Cleaning up a messy construct. Review of Educational Research, 1992. 62(3), 307-332.

Pangrazi, R. P., Beighle, A., \& Sidman, C. L. Pedometer power: Using pedometers in school and community. Champaign, IL 2007. Human Kinetics.

Prusak, K. A., Treasure, D. C., Darst, P. W., \& Pangrazi, R. P. The effects of choice on the motivation of adolescent girls in physical education. Journal of Teaching in Physical Education, 2004. 23(1), $19-29$.

Sallis, J. F. \& Owen, N. Physical activity and behavioural medicine. Thousand Oaks, CA1999. Sage.

Sallis, J. F., Prochaska, J. J, \& Taylor, W. C. A review of correlates of physical activity of children and adolescents. Medicine and Science in Sports and Exercise, 2000. 32, 963-975.

Sallis, J. F. Age-related decline in physical activity: a synthesis of human and animal studies. Med Sci Sport Exer, 2000. 32, 1598-600.

Saris, W. H. Habitual physical activity in children: Methodology and findings in health and disease. Med Sci Sport Exer, 1986. 18, 253-263.

Saris, W. H. M., \& Binkhorst, R. A. The use of pedometers and actometers in studying daily physical activity in man. Part II: Validity of pedometer and actometer measuring the daily physical activity. Eur J Appl Physiol, 1977. 37, 229-235.

Spear, B. A. Adolescent growth and development. Journal of the American Dietetic Association, 2002. 102(3), S23S29.

Stelzer, J., Ernest, J. M., Fenster, M. J., \& Langford, G. Attitudes toward physical education: A study of high school students from four countries - Austria, Czech Republic, England, and USA. College Student Journal, 2004, June. 38 (2), 171-179.

Stone, E. J., McKenzie, T. L., Welk, G. J., at al. Effects of physical activity interventions in youth: review and synthesis. Am J Prev Med, 1998. 15, 298-315. 
Strauss, R. S., Rodzilsky, D., Burack, G., \& Colin, M. Psychosocial correlates of physical activity in healthy children. Archives of Pediatric and Adolescent Medicine, 2001. 155(8), 897-902.

Tolson, H. An adjunct to statistical significance: $\omega^{2}$. Res Q Exercise Sport, 1980. 51(3), 580-584.

Trost et al. Age and gender differences in objectively measured physical activity in youth. Med Sci Sport Exer, 2002. 34(2), 350-355.

U.S. Department of Health and Human Services. Physical Activity Guidelines for Americans. Washington, DC 2008. U.S. Department of Health and Human Services.

Vincent, S. D., \& Pangrazi, R. P. Does reactivity exist in children when measuring activity levels with pedometers? Pediatr Exerc Sci, 2002. 14, 56-63.

Wang, G. Y., Pereira, B., \& Mota, J. Indoor physical education measured by heart rate monitor. Journal of Sports Medicine and Physical Fitness, 2005. 45(2), 171-177.

\section{Acknowledgement}

This work was supported by Grant Number 6198959221 from the Ministry of Education, Youth and Sport of the Czech Republic.

\section{Corresponding author}

\section{Krzysztof Skalik}

Academy of Physical Education in Katowice

72A, Mikołowska str., 40-065 Katowice, Poland

Phone: +48 322075157

Fax: +48 322075200

e-mail: k.skalik@awf.katowice.pl 